\title{
Electromagnetic Hemming of Aluminum Sheets using FEM
}

\author{
A. $\operatorname{Rajak}^{1 *}, \mathbf{S}$. Kore ${ }^{2}$ \\ ${ }^{1}$ Research Scholar, ${ }^{2}$ Assiciate Professor,Indian Institute of Technology Guwahati, Assam-781039, India \\ \{a.rajak@iitg.ernet.in\}
}

\begin{abstract}
Hemming is a metal sheet forming procedure to obtain tight fit or minimum gap when folding of sheet edges takes place over another. Bending of sheet metal edges takes place to $180^{\circ}$ in the last step of production line. This process is assumed to be a critical as it affects the surface quality of any enclosure of an automobile. Electromagnetic(EM) forming process is a high speed metal forming method where material with good electrical conductivity like aluminum alloys forming takes place by means of very high EM pressure. This article shows the numerical simulation of EM hemming process on Al 1050 series. Effect of variation in EM voltage on magnetic pressure, hemming union radius, warp curvature has been discussed.
\end{abstract}

Keywords: Hemming, Electro Magnetic (EM), Aluminum

\section{Introduction}

Hemming is a metal sheet forming process to obtain tight fit or minimum gap when folding of sheet edges takes place over another. Usually hemming operations are used to connect parts together and to reinforce part edges so as to improve the appearance of any automobile enclosure. In any automobile production, after deep drawing flanging and trimming, hemming is used in assembly as a secondary and essential operation for joining two metal sheets together [1]. Typical parts like trunk lids, hoods, fenders and doors are shown in Fig. 1

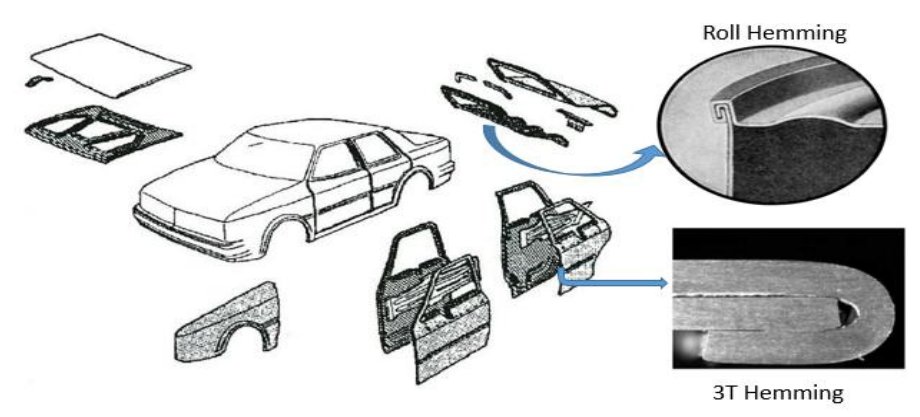

Fig. 1. Different hemmed parts of the automobile body

To maintain the appearance of surface quality in any production process, more accuracy is need to be maintained in a hemming process. Some important defects which occurs while hemming operations takes place are wrinkles or splits over the flange, overlap of the material in the corners or roll in [2]. To significantly reduce the number of "trial and error" loops during production, it is important to use simulation tools to better understand the hemming process. Compared to steel, aluminium has lower formability creating susceptible to localized strain in hemming process. Other researchers [3] have annealing the deformed area after the bending operation to reduce the hemming union radius. But integrating the heating step in continuous production line is a difficult and complex process [2]. The EMH (Electro Magnetic Hemming) is carried out using capacitor bank which is connected in series with resistance and inductor as shown in Fig. 2. RLC values of the circuit are calculated to operate in overdamped condition [4]. When a high intensity current is discharged from the circuit, due to magnetic field generated by the coil, an induced current is developed on the outer surface of the metal sheet as per Lenz's Law.

B. Iyer, S. Nalbalwar and R. Pawade (Eds.)

ICCASP/ICMMD-2016. Advances in Intelligent Systems Research.

Vol. 137, Pp. 77-82.

(C) 2017. The authors - Published by Atlantis Press

This is an open access article under the CC BY-NC license (http://creativecommons.org/licens)es/by-nc/4.0/). 
Because the direction of induces current is in opposite direction, repulsive Lorentz force is created between the workpiece and the rigid coil where velocities exceeds more than $300 \mathrm{~m} / \mathrm{s}$.

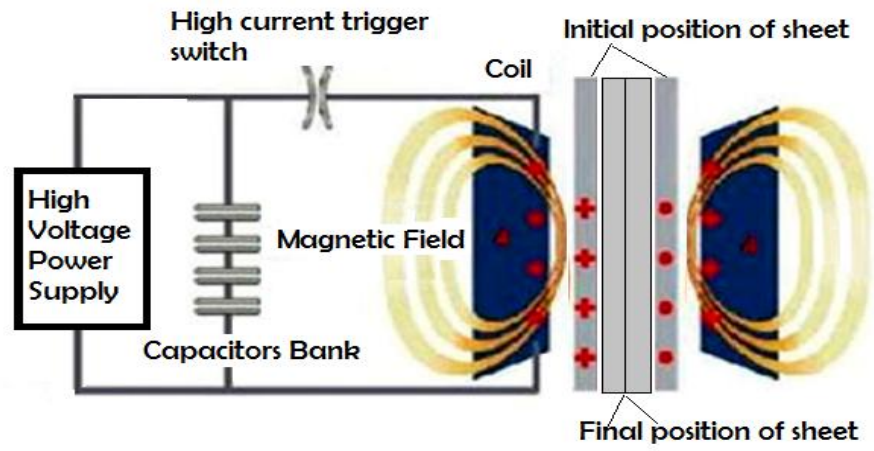

Fig. 2. Basic component of magnetic hemming process

The Johnson-Cook constitutive equations which is a combination of plastic strain and plastic strain rate were used to model the behaviour of deforming sheets in simulations.

$\sigma=\left(A+B \varepsilon^{n}\right)\left[1+C \ln \left(\frac{\dot{\varepsilon}}{\dot{\varepsilon_{o}}}\right)\right]\left[1-\left(\frac{T-T_{\text {room }}}{T_{m}-T_{\text {room }}}\right)^{n}\right]$

As shown in Eq. (1), it uses stain hardening, strain rate and thermal softening in a separable effect. Where $\sigma$ represents the equivalent plastic stress, $\varepsilon, \dot{\varepsilon}, \dot{\varepsilon}_{0}, \mathrm{~T}, \mathrm{~T}_{\mathrm{m}}, \mathrm{T}_{\text {room }}$ are equivalent plastic strain, plastic strain rate, reference equivalent plastic strain rate, temperature, melting temperature of the material and ambient room temperature. A, B, C, m and $\mathrm{n}$ are the constant values which are obtained from the mechanical tests [5]. Johnson-Cook material properties for aluminium and copper are shown in Table 1.

Table 1 Material properties used for simulations [6]

\begin{tabular}{|lllllll|}
\hline Materials & $\mathrm{A}(\mathrm{MPa})$ & $\mathrm{B}(\mathrm{MPa})$ & $\mathrm{n}$ & $\mathrm{C}$ & $\mathrm{T}_{\mathrm{m}}(\mathrm{K})$ & $\mathrm{m}$ \\
\hline $\mathrm{AA} 1050$ & 110 & 150 & 0.36 & 0.014 & 918 & 1 \\
\hline $\mathrm{Cu}$ & 90 & 292 & 0.31 & 0.025 & 1331 & 1.09 \\
\hline
\end{tabular}

Material properties of $\mathrm{Al} 1050$ and copper used for the simulation in the EM module of the finite element software LS-DYNA is listed in Table 2.

Table 1 Material properties for tube Al 1050 and $\mathrm{Cu}$

\begin{tabular}{|llllll|}
\hline Material & Density $(\rho)$ & $\begin{array}{l}\text { Modulus of } \\
\text { Elasticity } \\
(\mathrm{E})\end{array}$ & $\begin{array}{l}\text { Poisson's } \\
\text { Ratio }(\gamma)\end{array}$ & $\begin{array}{l}\text { Thermal } \\
\text { Conductivity } \\
(\mathrm{k})\end{array}$ & $\begin{array}{l}\text { Electrical } \\
\text { resistivity }(\rho)\end{array}$ \\
\hline $\mathrm{AA} 1050$ & $2705 \mathrm{Kg} \mathrm{m}^{-3}$ & $69 \mathrm{GPa}$ & 0.33 & $368 \mathrm{~W} \mathrm{~m}^{-1} \mathrm{~K}^{-1}$ & $2.9 \times 10^{-8} \Omega \mathrm{m}$ \\
\hline $\mathrm{Cu}$ & $8960 \mathrm{Kg} \mathrm{m}^{-3}$ & $124 \mathrm{GPa}$ & 0.27 & $596 \mathrm{~W} \mathrm{~m}^{-1} \mathrm{~K}^{-1}$ & $1.7 \times 10^{-8} \Omega \mathrm{m}$ \\
\hline
\end{tabular}

\section{Model Description}

Simulations were carried with different voltages with the same unchanged coil geometry which is made rigid to make it simple for calculation in boundary element method. The Range of voltage was varied from $4 \mathrm{kV}$ to 12 $\mathrm{kV}$. Initially, $2 \mathrm{~mm}$ standoff distance was positioned so that proper selection of the voltage of the required coil 
geometry can be found. The Dimension of the coil and nomenclature used in the simulation are depicted in Figure 3.

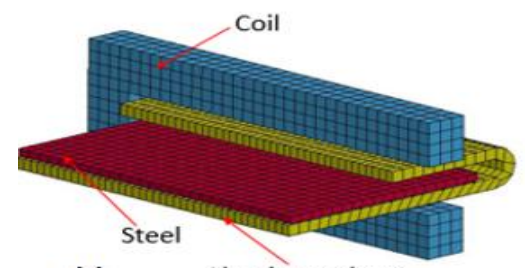

(a)

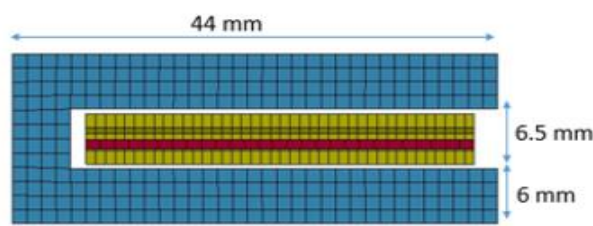

(c)

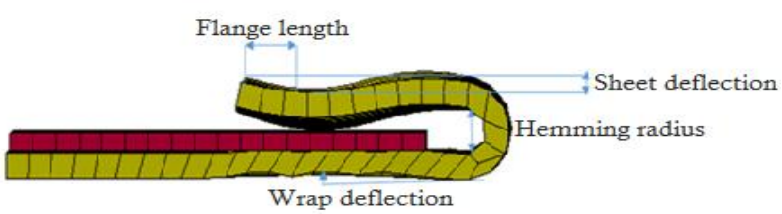

(b)

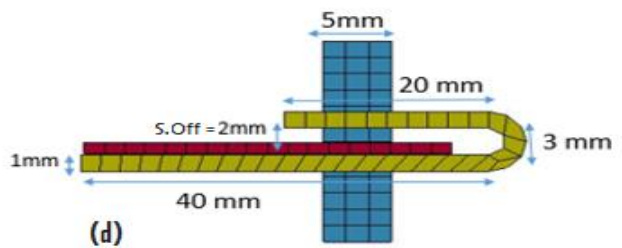

Fig. 3. Illustration of the model developed for simulation in LS Dyana EM module

Deformation pattern obtained during the simulation at different discharge voltages is shown in Fig. 4. The range of voltage was varied from $4 \mathrm{kV}$ to $12 \mathrm{kV}$ to check the deformation of the sheets. Initially, $2 \mathrm{~mm}$ standoff distance was maintained so that proper selection of the voltage for the required coil geometry can be found.

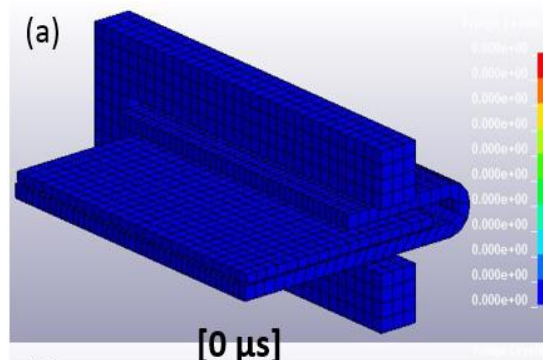

(d)

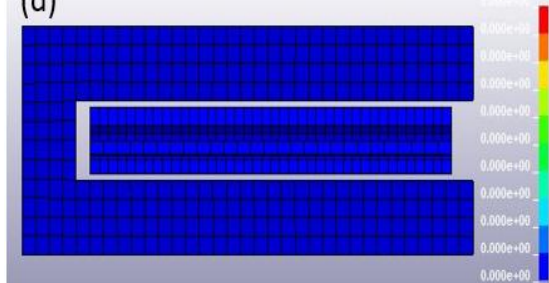

(b)

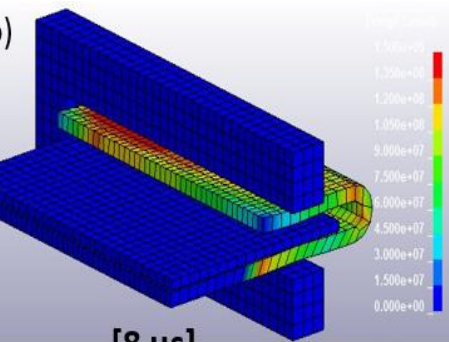

(e)

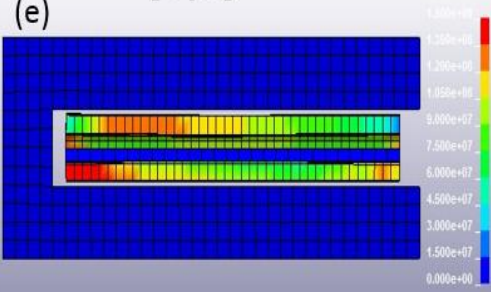

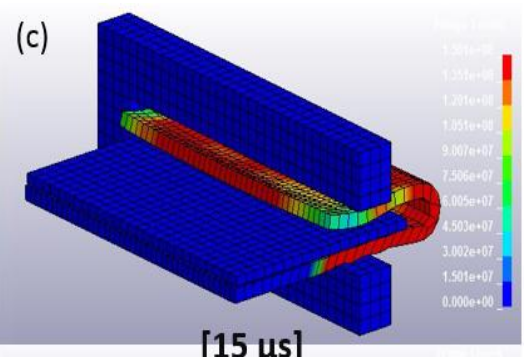

(f)

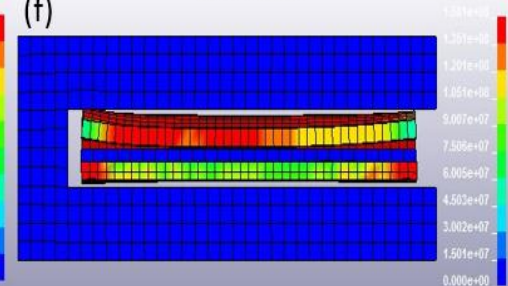

Fig. 4. Simulated geometry of the sheet at $0 \mu \mathrm{s}, 8 \mu \mathrm{s}$ and $15 \mu \mathrm{s}$ where a, b and c represents the isometric view with maximum Von Mises stress value of $15 \mathrm{MPa}$ and $\mathrm{d}$, e and $\mathrm{f}$ shows the subsequent left cross sectional view.

\section{Results and Discussion}

\subsection{Variation of pressure and time.}

Elements were selected on the top surface of the deformed sheet and a maximum pressure of 50 MPa was observed as shown in Fig. 5. In order to get a proper hemming joint, the magnetic pressure must be high, otherwise, the sheet will impact with lower velocity resulting in insufficient deformation. It was found that after $14 \mu \mathrm{s}$ there is a sudden change in pressure in negative direction of $7.69 \mathrm{MPa}$, that is due to the rebound effect which occurs when a softer material (aluminium) makes an impact with the harder material (steel). For better contact between the sheets, value or rebound pressure should be minimum. 


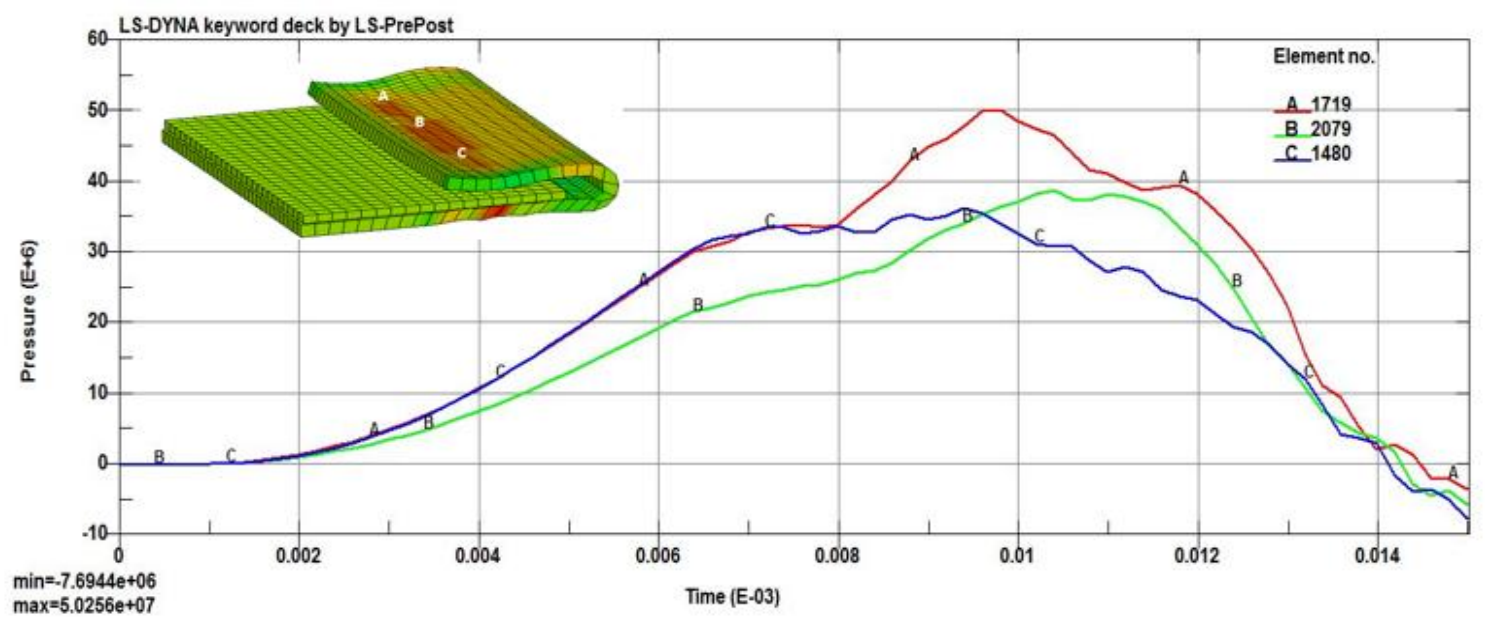

Fig. 5. Pressure graph obtained in EM simulated model

\subsection{Variation of sheet displacement and time.}

A minimum gap must exist to gain velocity and acquire kinetic energy to get sufficient impact energy. For proper hemming, there is an optimum value of standoff distance. Standoff distance changes the kinetic energy so the impact energy. As shown in Fig. 6, a standoff distance of $2 \mathrm{~mm}$ was maintained and displacement of flyer sheet was found to be $1.204 \mathrm{~mm}$. While warp deflection was found to be $0.21 \mathrm{~mm}$. In the case of higher standoff distance, the velocity drops to a lower value resulting in lower impact energy.

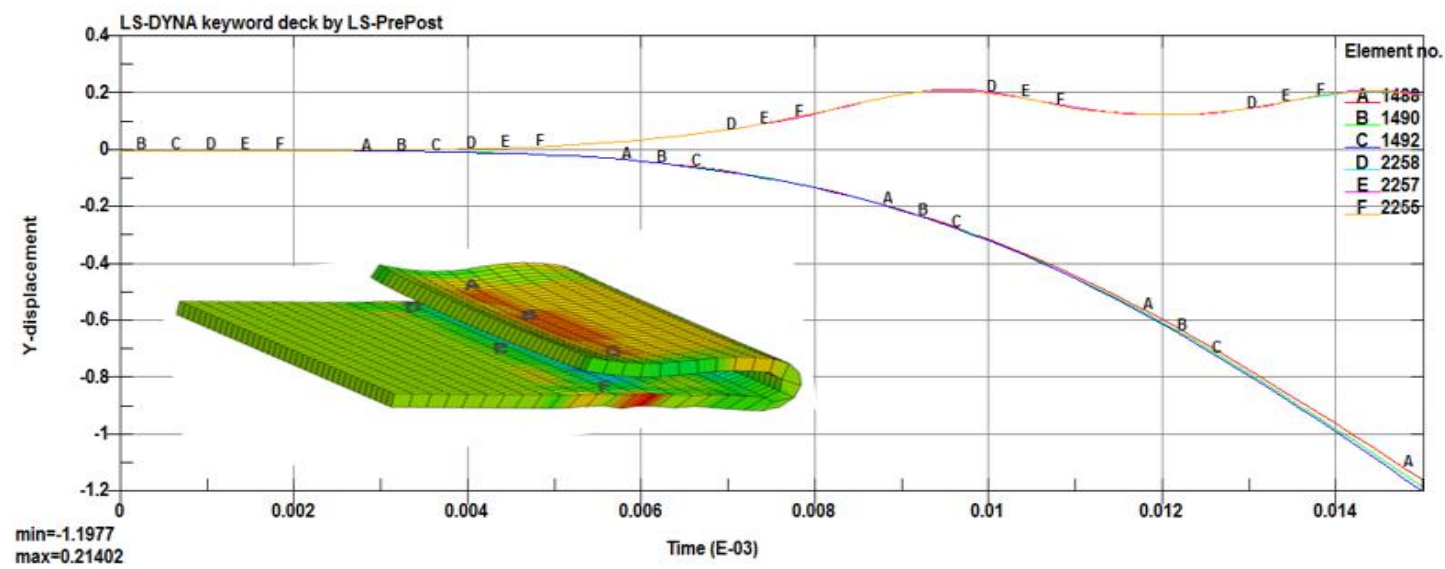

Fig. 6. Displacement graph in EM hemming simulation is shown in above graph, where A, B and C shows the corner deflection and D, E and F are wrap deflection

\subsection{Current density and Lorentz force}

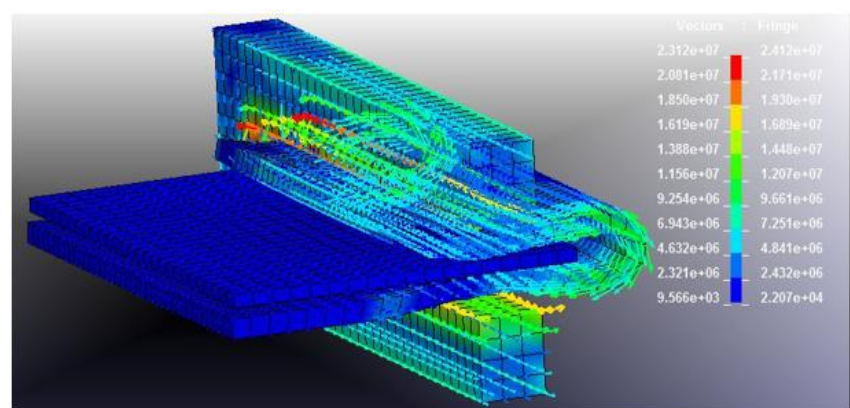

(a)

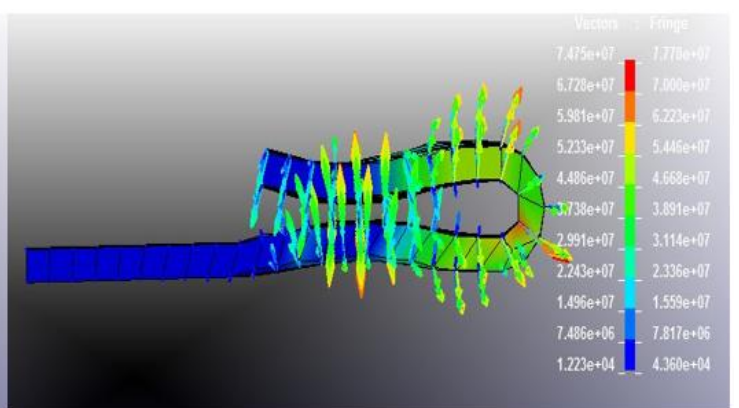

(b)

Fig. 7. (a) Distribution of current over the EM model (b) Lorentz force vector distribution over the plate 
As current start to flow through the coil it generates the magnetic field around it. When this magnetic field passes through the Al sheet an eddy current is induced. Fig. 7(a) shows the maximum current density of 241 kamps $/ \mathrm{m} 2$. Vector lines in the figure represent the direction of the flow of the current inside the coil. In Fig. 7(b) sheet is experiencing a Lorentz force of magnitude of more than $77 \mathrm{kN}$. In rebound region, a Lorentz of more than $77 \mathrm{KN}$ was observed. So it can be predicted that the higher value of Lorentz force results in the rebound effect [7].

\subsection{Variation of rebound pressure and voltage}

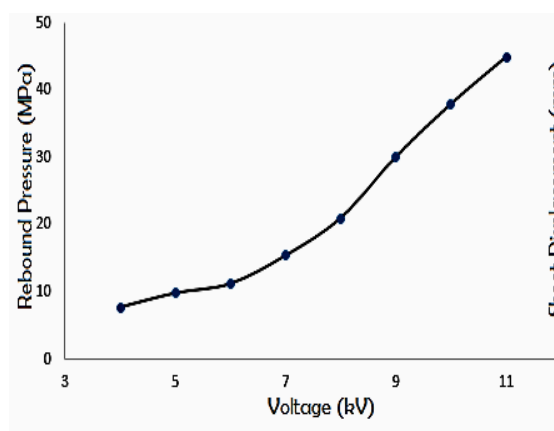

(a)

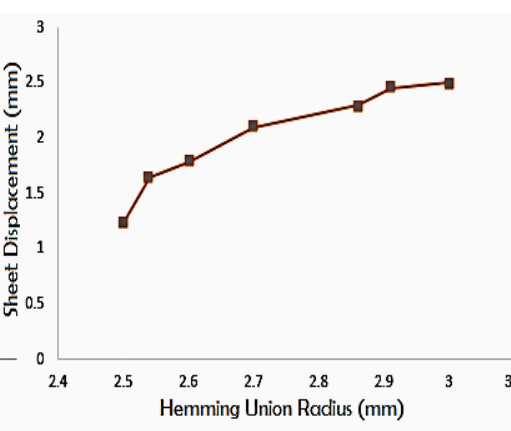

(b)

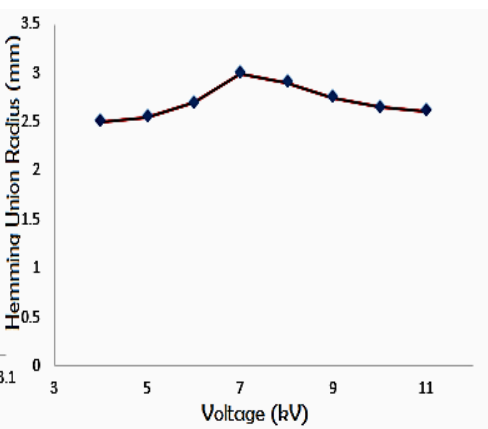

(c)

Fig. 8. (a) Plot in graph showing increase in corner deflection with increase in hemming radius, (b) Variation of hemming radius with change in voltage

Maximum rebound pressure was studied for varying voltages and plotted in Fig. 8 (a). It has been found that with the increase in the voltage value of rebound pressure keeps increasing. Because of intricate deformation at the interface and Lorentz force acting perpendicularly rebound occurs [7]

\subsection{Variation of sheet displacement and hemming union radius}

Sheet displacement to hemming union radius has been plotted in Fig. 8 (b). For a proper hemming process, it is important that hemming radius remains least affected [2]. It has been found that sheet deflection keeps increasing with increase in hemming union radius due to increasing in of the standoff distance. The standoff distance and hemming union radius need to be chosen very carefully to ensure proper contact between sheets.

\subsection{Variation of hemming union radius and voltage}

The effects of voltage input on the hemming union radius was studied. The hemming union radius increases with the increase of energy input from $4 \mathrm{kV}$ to $7 \mathrm{kV}$ as shown in Fig. 8 (c). But when the energy input is increased to $11 \mathrm{kV}$, the hemming union radius decreased to $2.6 \mathrm{~mm}$. It was because with the increase in voltage, concentration of current density increases over the deforming region resulting in increase in the rebound pressure.

\section{Conclusions}

The finite element analysis of electromagnetic hemming was carried out to study process. It has been found that rebound pressure was significantly affected by the input voltage. For better contact between the sheets, value or rebound pressure should be minimum Maximum pressure was found to be $50 \mathrm{MPa}$ with a rebound pressure of 7.6 MPa. Deflection of $1.19 \mathrm{~mm}$ was found in simulation results with minimum wrap deflection of $0.21 \mathrm{~mm}$. Further sheet deflection and hemming union radius have been discussed. Experimental studies of the current simulation work will be a further scope of the study. 


\section{References}

[1]. Kenichiro Mori Niels Bay, Livan Fratini, Fabrizio Micari, A. Erman Tekkaya, "Joining by plastic deformation", J. Manufacturing Technology, 62(2013) 673-694.

[2]. P. Jimbert, I. Eguia, I. Perez, A. M. Gutierrez and I. Hurtado, "Analysis and comparative study of factors affecting quality in the hemming of 6016T4AA performed by means of electromagnetic forming and process characterization“, J. Mater. Process. Technology, 211(2011) 916-924.

[3]. P. Krajewski and J. Carsley, "Heat Treatment Effects on Bending in AA6111 Aluminum" TMS (2003) 25-35

[4]. G. Zhang H. Hao, X. Wu, S.J. Hu, K. Harper, and W. Faitel, “An Experimental Investigation of Curved Surface-Straight Edge Hemming”, J. Manuf Processes 2(2000) 241-246.

[5]. Elsen, M. Ludwig, R. Schaefer and P. Groche," Fundamentals of EMPT Welding", 4th International Conference on High Speed Forming (2010) 117-126.

[6]. Stakvik Eide Hilde Olaug and Melby Emil Arne, "Blast Loaded Aluminium Plates", Report Department of Structural Engineering NTNU Norwegian University of Science and Technology, 2013.

[7]. Kore S D, Date P P and Kulkarni S V, "Electromagnetic Impact Welding of Aluminum to stainless steel sheets", J. Mater. Process. Technology, 208(2008) 486-493. 